\title{
Socio-ecological resilience to climate change effects in peri-urban areas: insights from the Pugu and Kazimzumbwi forest reserves of Dar es Salaam, Tanzania
}

\author{
Lazaro Eliyah Mngumi $[$ (])
}

Published online: 4 September 2019

(C) The Author(s) 2019

\begin{abstract}
This article is exploring socio-ecological system adaptive capacities for building resilience to climate change effects in the peri-urban belt of Dar es Salaam, at the Pugu and Kazimzumbwi forest reserves. Three selected hamlets (Nzasa, Kisarawe and Pugu-Kibaoni) constitute the study area. A combination of household interview, key informant interview, focus group discussion complemented by literature review compose data collection techniques deployed. The study revealed diverse socio-ecological system 'adaptive capacities' for building resilience to climate change effects. These includes socio-cultural i.e. heterogenous ethnic groups, promising literacy rate, diverse age cohorts within the population and diverse occupations. Another set of adaptive capacities at Pugu and Kazimzumbwi socio-ecological system regards diverse and innovative ecosystem services based income generating activities i.e. Bee keeping industry and tourism industry in its multiple forms (food tourism, arts and craft tourism and nature tourism). Overall, the Pugu and Kazimzumbwi socio-
\end{abstract}

L. E. Mngumi ( $₫)$

Institute of Human Settlements Studies (IHSS), Ardhi University, P.O. Box 35176, Dar es Salaam, Tanzania e-mail: lazaromngumi@gmail.com;

lazaro.mngumi@slu.se

\section{E. Mngumi}

Faculty of Natural Resources and Agricultural Sciences, Swedish University of Agricultural Sciences (SLU), P.O. Box 7012, 75007 Uppsala, Sweden ecological system has considerable adaptive capacities providing ample platform for agents to act upon in building resilience to climate change effects. It is hereby recommended that the nature, role and extent of agency be explored so as to establish the status quo and therefore the feasible entry point for policy intervention.

Keywords Provisioning ecosystem services . Cultural ecosystem services - Adaptive capacities . Economic diversity $\cdot$ Peri-urban

\section{Introduction}

Climate change is no longer an abstract concept but a lived experience in both urban and peri-urban areas in Dar es Salaam (IPCC 2007, 2014; Lupala and Maglan 2015; Secretariat 2017). Despite considerable attempts to address both causes and effects of climate change through mitigation and adaptation initiatives, studies (Secretariat 2017; Lupala and Maglan 2015; IPCC 2007), substantiate its continued existence and further project its uncertain future. However, given contrasting levels of development between urban and peri-urban areas, the effects of climate change are crutially differentiated. In Dar es Salaam city in Tanzania for instance, notable effects of climate change in urban areas includes frequent flooding and 
sea-level rise (Secretariat 2017), while in peri-urban areas dominant effects includes decreasing crop yield leading to increased encroachment of reserved forest ecosystem services (Lupala and Maglan 2015). Encroaching forest ecosystem services forms part of the autonomous adaptation strategies to climate change effects by the peri-urban communities. These autonomous adaptation strategies not only bring about conflict between the local communities and authorities responsible for managing the forest reserves but also leads to maladaptation (Ricci 2015). Accordingly, studies recommend robust strategies geared at enhancing community resilience to climate change effects in peri-urban areas of Dar es Salaam for win-win-win outcome. On the other hand ecosystem-based solutions to climate change effects have been at the forefront since last decade at both international policy arena and within scientific community (Vignola et al. 2009; Munang et al. 2013). Interestingly however, ecosystem services are increasingly regarded to have enormous potential in building resilience for climate change effects to urban and peri-urban communities (Munroe et al. 2012). Unfortunately, little if anything has been done in exploring the possibilities of deploying this emerging discourse in building resilience to climate change effects in peri-urban areas in Sub-Saharan Africa (SSA) and Dar es Salaam city in particular.

Peri-urban is one of the increasingly used concept by both scholars and proffessionals inferring to a zone of intersection between urban and rural landscapes (Birkmann et al. 2010). Despite lacking a unified conceptualization, there is a growing understanding on mutual-existing of both urban and rural features within cities and beyond their jurisdictions (Salem 2015). In other words, peri-urban connotes the transition zones with some degree of intermingling of urban and rural functions (Wandl and Magoni 2016). The two entities, i.e. urban and rural areas, are argued to be interdependent, and the peri-urban area convene the point of intersection between the two (Birkmann et al. 2010). In this article the concept i.e. 'peri-urban' is used to connote the Pugu and Kazimzumbwi forest reserves (Fig. 1) located along the outskirts of the city of Dar es Salaam, the business capital of Tanzania. Similar to other peri-urban areas in SSA (Roy et al. 2017), ecosystem services in these forest reserves are increasingly urged to be deteriorating.

Against this preamble, this article analyses the adaptive capacities of the peri-urban socio-ecological system using the Pugu and Kazimzumbwi forest reserves as the case study. The analysis provide a stepping stone towards building socio-ecological resilience to climate change effects through enhanced 'provisioning and cultural' ecosystem services. The article first discusses the theoretical concepts laying the basis for the analysis and discussion of the emperical findings. Analysis of the current state of the art on climate change experience, effects and its implicature on diminishing of the peri-urban ecosystem services are presented. Furthermore, socio-ecological and yet latent adaptive capacities for building resilience to climate change effects at the Pugu and Kazimzumbwi socio-ecological system are presented followed by the discussion on how they can be revitalized.

\section{Theoretical tenets}

Community resilience is increasingly understood in terms of relationship between people and ecosystems as integrated social-ecological systems whereby social systems and ecosystems are recognized as intertwined, interdependent and co-evolving (Berkes et al. 2000; Folke 2006). Social and ecological systems are linked in synergistic and coevulutionary relationships (Norgaard 1994). 'Thus resilience of social systems is related in some ways to the resilience of the ecological systems on which social systems depend' (Adger 2000). The confluence between ecosystem resilience and social resilience have been expounded across disciplines, including ecological economics, human ecology and human geography (Gunderson 1997; Zimmerer 1994). This is apparently illustrated in a scenario whereby social institution (system) is interwoven within a single ecosystem or single resource (Adger 2000).

However, there are tenets to be adhered to when applying resilience concept from ecology to social institutions, owing to the fact that there exists marked differences in behaviour and structure between 


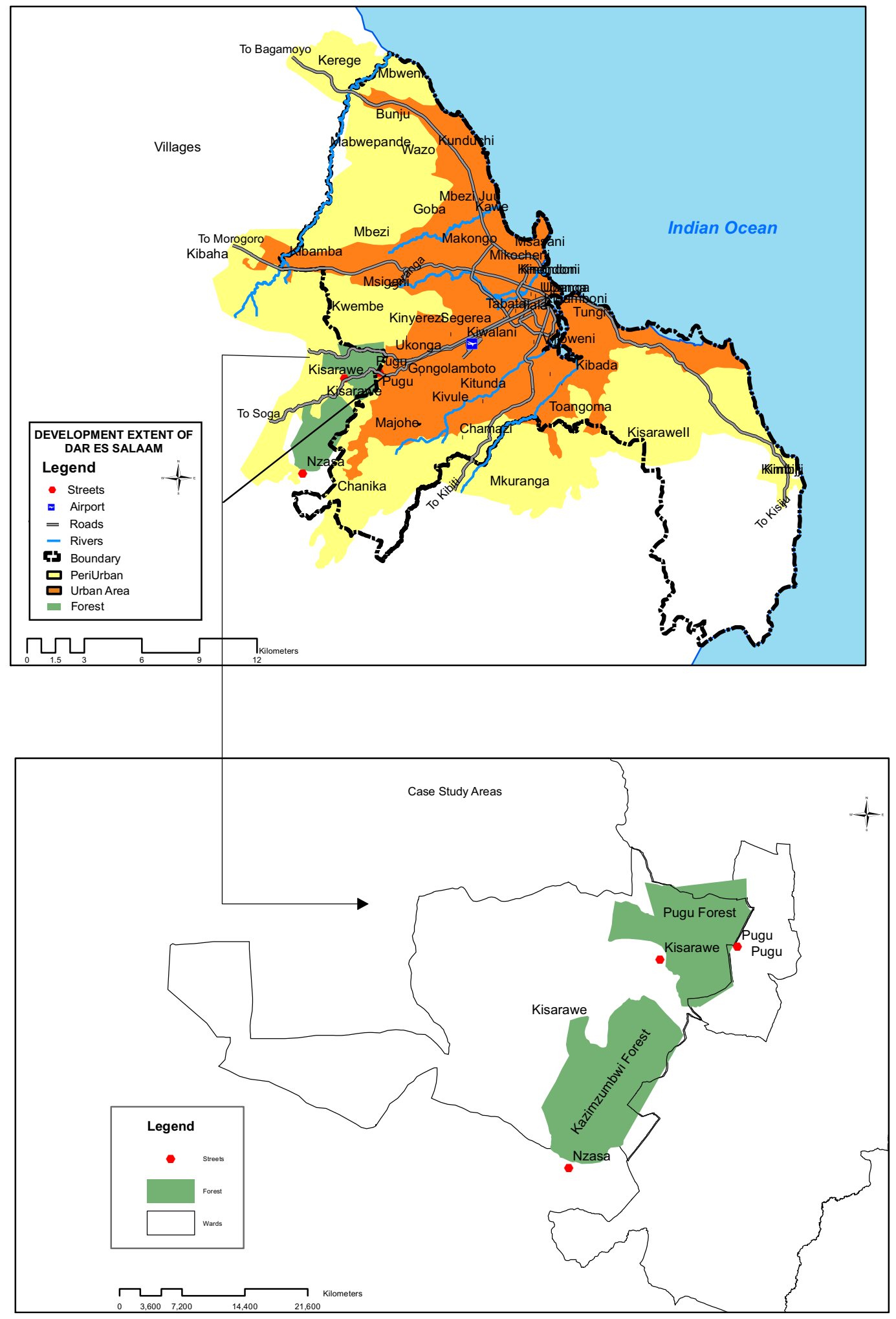

Fig. 1 Study area at the peri-urban of Dar es Salaam city, Tanzania 
socialized institutions and ecological systems (Adger 2000). An imperative tenet pertains to the question of dependency of social systems on the ecosystem services. Are communities depending on ecosystem services themselves crutially linked to the resilience of the ecosystem? In other words this tenet posit that there should be direct linkages between ecosystem and social resilience for using analogies of ecological resilience into social systems resilience i.e. socialecological system resilience (Ibid).

The term social-ecological systems have been used consistently in the resilience literature since 2000 instead of "communities" (Berkes and Ross 2013). Specifically, the term i.e. social-ecological systems has been used to connote a resource-dependent community or an indigenous community that affiliates culturally with a local environment and depends heavily on local resources (Lu 2010).

Community resilience similar to community dependence concepts are well applicable to place-based communities (Maida 2007), and less applicable to communities where people derive their living outside their locale (Almedom 2004). However, originating in rural sociology (Humphrey et al. 1993; Freudenburg and Gramling 1994), 'ecosystem services dependency' is strongly linked to extraction and processing of tangible raw materials such as forest products and fishery resources (Tidball and Stedman 2013). However, urban systems behave different from rural systems in that their direct dependence on tangible ecosystem services are relatively weaker and have heterogenous ways of how to use land (Ernstson 2008). It is further argued that urban system not only depend less on tangible (extractive) products but may depend more on intangible components of ecosystem services famously categorized as 'cultural ecosystem services'(MEA 2005a).

Community resilience is built as the community responds to shocks and stresses, and developing resilience through capacity building and social learning (Goldstein 2008). A typical example of shocks and/stress is climate change. Socio-ecological capacities assisting in building resilience from stress and shocks vary from community to community (Berkes and Ross 2013). Scholars; Gooch et al. (2010), Ross et al. (2010), Hegney et al. (2008), Kulig et al. (2009),
Norris et al. (2008) have proposed a set of community adaptive capacities playing key role in resilience building including; people-place connections; cultural values; knowledge; skills and learning; social capital; engaged governance (involving collaborative institutions); a diverse and innovative economy; community infrastructure; leadership and positive outlook, including readiness to accept change.

Being one of the critical factors for building socialecological resilience (Folke et al. 2003), diverse and innovative economy tenet is closely linked to dependency metaphor. The more diversified economies the ecosystem dependent communities are the more resilient (Gunderson and Holling 1995; Szreter and Woolcock 2004; Biggs et al. 2015). Functional diversity or existence of alternatives that can serve similar purpose, can provide 'insuance' within a system by allowing some system parts to compensate failure of those parts affected by the shock and/stress (Biggs et al. 2015). Availability of a range of economic opportunities is one of the critical diversity aspect in resilience discourse (Berkes 2007; Ullsten et al. 2004). The primary idea behind diverse economy is that it offers ground for new opportunities in resilience building (Ullsten et al. 2004). It hence increases options for coping with shocks and stresses making the system more resilient (Berkes 2007; Ullsten et al. 2004). Diversity is even more imperative if its component parts react differently to change and disturbance. This is famously known as response diversity which is necessary for ensuring that a particular shock is unlikely to present the same risk to all components (Biggs et al. 2015). The diversity and innovative economy tenet is well embodied in the saying "dont put all your eggs in one basket". Contrary to conventional economic thinking promoting maximum efficiency, resilience discourse encourages policies that can enable coping with ecological, climate, market or conflict-related shocks (Biggs et al. 2015). Briggs and colleagues provide a typical example of a viable response diversity of livelihood in a farming community that 'it has to be options dissimilar to farming, such as eco-tourism and related activities instead of alternative ways of farming', such diversity ought to provide wider response diversity and hence resilience to shocks. Dependency on limited 
ecosystem services increases income variance and risk of failure of particular resource and as a result decreasing economic stability.

\section{Materials and methods}

Study area description

The Pugu and Kazimzumbwi Forest Reserves (PKFR), along the peri-urban belt of Dar es Salaam city in Tanzania (Fig. 1) forms the setting of the case study. Administratively, the PKFRs are largely under the jurisdiction of the Kisarawe District Council (KDC) in Coast Region of Tanzania. The two peri-urban forest reserves are of global importance as they support 37 endemic vertabrate species and about 554 endemic plants (Burgess 2000). These forests are remnants of few ancient forests in the world, and form the catchment area for Msimbazi, Mambizi, Mzumbwi, Vikongoro, Kimani, Nzasa and Nyeburu Rivers (TFCG 2013; Lupala et al. 2014). The Pugu forest gazetted as a reserve in 1954 lies in the northeastern part of the Pugu Hills, about $25 \mathrm{~km}$ southwest of Dar es Salaam and $20 \mathrm{~km}$ from the Indian Ocean, and adjacent to the Kazimzumbwi Forest Reserve gazetted in the 1936 (Clarke and Dickinson 1995).

The Indian Ocean tropical monsoon climate is influencing rainfall characteristics of both forests. The two peri-urban forests are characterized by bimodal rainfall pattern i.e. long rains between late March and early June popularly known as Masika and short rains between October and December famously known as Vuli. Rainfall is averaging at approximately $1100 \mathrm{~mm}$ per year. Temperature ranges from 24 to 31 varying with elevation (Clarke and Dickinson 1995; Lupala and Maglan 2015). Topographically, the two forests reserves are positioned between 100-305 and 120-280 $\mathrm{m}$ above the sea level respectively (TFCG 2013).

The study was done in three hamlets (MITAA), two hamlets are adjacent to the Pugu forest reserve i.e. Pugu-Kibaoni and Kisarawe and Nzasa hamlet is located adjacent to the Kazimzumbwi forest reserve (Fig. 1). The three study hamlets were purposevely selected for the sake of unearthing hybrid mix of the Pugu and Kazimzumbwi forest reserves-socio-ecological system adaptive capacities for building resilience to climate change effects.
Methods

Case study, a preferred approach in characterizing local knowledge on ecosystem services (Lamarque et al. 2011) was employed. Literature review, household survey, key informant interviews (KIIs) and focus group discussions (FGDs) comprise the techniques employed in collecting field data. Literature review guide, household questionnaire, key informant interview guide and focus group discussion guide are the respective tools used in collecting data on various adaptive capacities of the Pugu and Kazimzumbwi forest reserves-socio-ecological system. Both FGDs and KIIs were used to gather information on various adaptive capacities at the named peri-urban forest reserves. Household interviews complemented the two aforementioned data collection techniques i.e. FGDs and KIIs. Literature review on the other hand was used to map climate change effects at the periurban socio-ecological system.

Data collection techniques were administered sequentially. The first technique to be employed was focus group discussion, followed by key informant interview and lastly household interview. Focus group discussion was the first technique to be administered for two main reasons i.e. identifying potential candidates for key informant interviews and fine tuning the questionnaire ready for household interview. Three (3) focus group discussions were held one in each study hamlet. Each FGD was composed of seven community members selected by the help of the hamlet (MTAA) chairman. Village environmental committee composed majority of the FGD members as they were well informed of the subject under consideration. A total of fifty (50) questionnaires were randomly administered in each of the study hamlet amounting to one hundred and fifty (150) in the entire study area. The 50 households per hamlet is approximated to $10 \%$ household per hamlet. Regarding key informant interview, a total of nine (9) key informant interviews were conducted. However, literature review did not follow the aforementioned as it was done concurrent with other techniques.

\section{Data collection execution}

In all the three study hamlets, interview consent was requested beforehand from all participants so as to be able to take notes of the conversations. This was done 
to comply with ethical requirements and to request if participants could feel comfortable to tape record the interviews. Participants in all the three hamlets were however not supportive to the request of tape recording the conversations and in turn they requested anonymity of their responses, so I thought it wise note to record the conversation so as to make them feel at easy and be free in expressing their views. Responses were anonymised for creating more freedom of expression to interviewees while expressing themselves as requested by participants.

A semi-structured interview approach was employed in gathering information in both focus group discussions (FGDs) and Key informant interviews (KIIs). Ecosystem services were introduced to participants in locally relevant terms based on how they have been used in their local environment. Localuser-friendly terms such as bee keeping and/bee products, firewood, timber, tourism attractions were key terms used in the discussion. This was crucial in bringing participants in the same 'page' and so bridging cultural differences in ecosystem services conception between the academia and the local community. Interviews anchored upon socio-ecological system capacities and how ecosystem services (provisioning and cultural) can be useful in building resilience to climate change effects. At the end of every conversation after exhaustive unearthing of various interview themes, interviewees consent on views anonymity was re-confirmed and were thanked for their time and generous cooperation.

Household interview via structured (close-ended) questionnaire was proceeded by 2 days enumerators training. The training was aimed at ensuring clear understanding of the main themes of the questionnaire and specific questions and likely response by the enumerators. This was necessary as enumerator's work involved asking questions to respondents, clarifying where the question was unclear to respondents and filling the questionnaire after receiving response from interviewees. This was again crutial so as to ensure maximum response as some respondents could not read and right (Table 1). At every evening of the field work, a brief overview with enumerators was held on how the work was done on a day including cross checking the filling of questionnaires and planning for the day ahead. This was necessary to check the work progress and address the challenges if any for ensuring validity of the data collected.

Despite literature review being carried out throughout the research process, it was specifically demployed in exploring various information regarding climate change across all study themes at the peri-urban forest reserves of Pugu and Kazimzumbwi. The themes includes climate change effects on livelihoods and ecosystem services, community understanding of its presence and effects. Most of the reviewed literature in this case emanated from studies conducted between 2011 and 2015 under the climate change impacts, adaptation and mitigation (CCIAM) programme funded by the Royal Norwegian Government.

\section{Results and discussion}

An overview of ecosystem services and climate change effects

Ecosystem services in peri-urban areas of Dar es Salaam i.e. Pugu and Kazimzumbwi forest reserves have been declining over time (Lupala 2016). The diminishing of ecosystem services in these areas is attributed to the increase in anthropogenic activities leading to deforestation and forest degradation ( $\mathrm{Lu}-$ pala et al. 2014, Kashaigili et al. 2013b). Historically, the increasing anthropogenic activities is associated
Table 1 Respondent's level of education. Source: Field work (October 2017March 2018)

\begin{tabular}{lcccc}
\hline Level of education & \multicolumn{2}{l}{ Study hamlet in $\%$} & Total \\
\cline { 2 - 5 } & Nzasa $(\mathrm{N}=50)$ & Pugu-Kibaoni $(\mathrm{N}=48)$ & Kisarawe $(\mathrm{N}=49)$ & \\
\hline None & 16 & 2 & 3 & 21 \\
Primary education & 17 & 24 & 17 & 59 \\
Secondary education & 1 & 5 & 8 & 14 \\
Certificate and above & 0 & 1 & 5 & 6 \\
\hline
\end{tabular}


with the early 1970s villagilazation programme (Burgess and Dickinson 1993). The programme triggered rapid population growth and consequently clearence of forest and substantial land use change in these peri-urban forest reserves and the associated ecosystems (ibid). However, the rapid population growth is both historic, yet contemporary driver of declining peri-urban ecosystem services leading to high land demand for residential purposes (Burgess and Dickinson 1993, Lupala et al. 2014). According to Lupala et al. (2014), the population in settlements surrounding Pugu and Kazimzumwi forest reserves grew more than 39 times in 2012 from year 1967. Population increase in these peri-urban areas creates pressure on resources due to high land demand for settlements, farming etc.This in turn leads to forest encroachment and thereby decline of ecosystem services. The rapid population growth in these periurban areas overtime is evident when visualising the spatial growth of Dar es Salaam city along four aterial roads of Bagamoyo, Morogoro, Kilwa and Pugu (ibid). Lupala and colleagues further closely associates rapid population growth with increasing enroachment of nearby forest reserves and declining ecosystem services in both quality and quantity. Notable ecosystem services declined overtime at the Pugu and Kazimzumbwi forest reserves includes number of plant and animal species, amount of water from dams (Minaki) and rivers (Msimbazi, Mambizi, Mzumbwi,
Kimani, Vikongoro, Nzasa and Nyeburu), water quality and honey production (ibid).

Climate change constitute another intriguing driver for the declining peri-urban ecosystem services at the Pugu and Kazimzumbwi forest reserves (Lupala and Maglan 2015), and thereby posing ill-effects on community livelihoods (Kashaigili et al. 2013a, Lupala and Maglan 2015). A 30 years rainfall and temperature study (Figs. 2, 3) indicates decreasing rainfall and increasing temperature trends. Rainfall and temperature trends in these peri-urban forests echo perceptions by community members. Community members at the Pugu and Kazimzumbwi forest reserves mentioned; decreasing rainfall, unpredictable rainfall pattern using traditional knowledge, decreasing water amount in water sources, increasing temperature, increasing drought incidents, disappearing of wetlands, heavy storms, increasing flooding, increasing sediments in rivers, disappearing of plant and animal species as some of the indicators of climate change (Kashaigili et al. 2013a; Lupala and Maglan 2015; Lupala et al. 2014). Furthermore, community members surrounding the Pugu and Kazimzumbwi forest reserves associate climate change with livelihood related impacts (Lupala and Maglan 2015; Kashaigili et al. 2013a). Some of the identified impacts of climate change related to livelihoods are declining food crop production leading to food insecurity, and eventual decreasing saving pronspensity (Lupala and

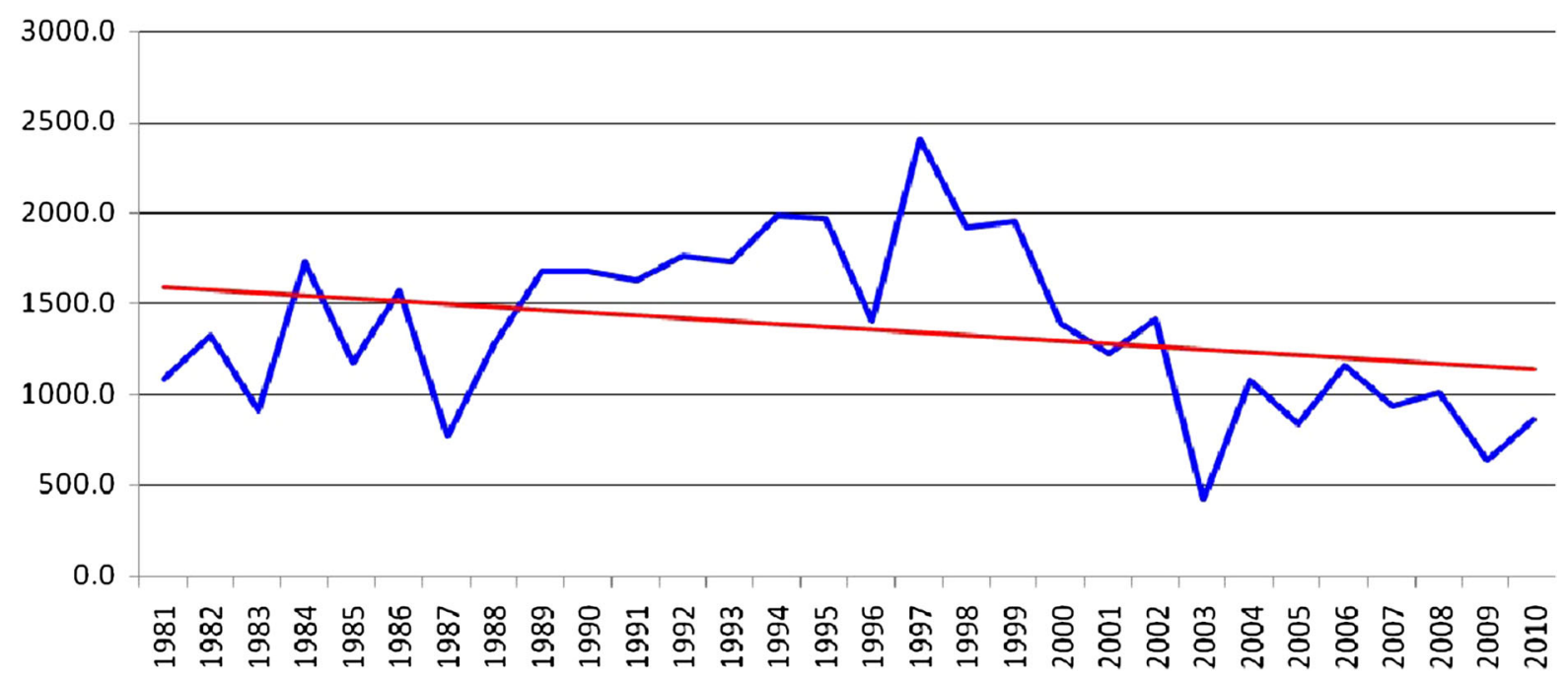

Fig. 2 Trend in rainfall amount for Kisarawe in millimetres (1981-2010) 


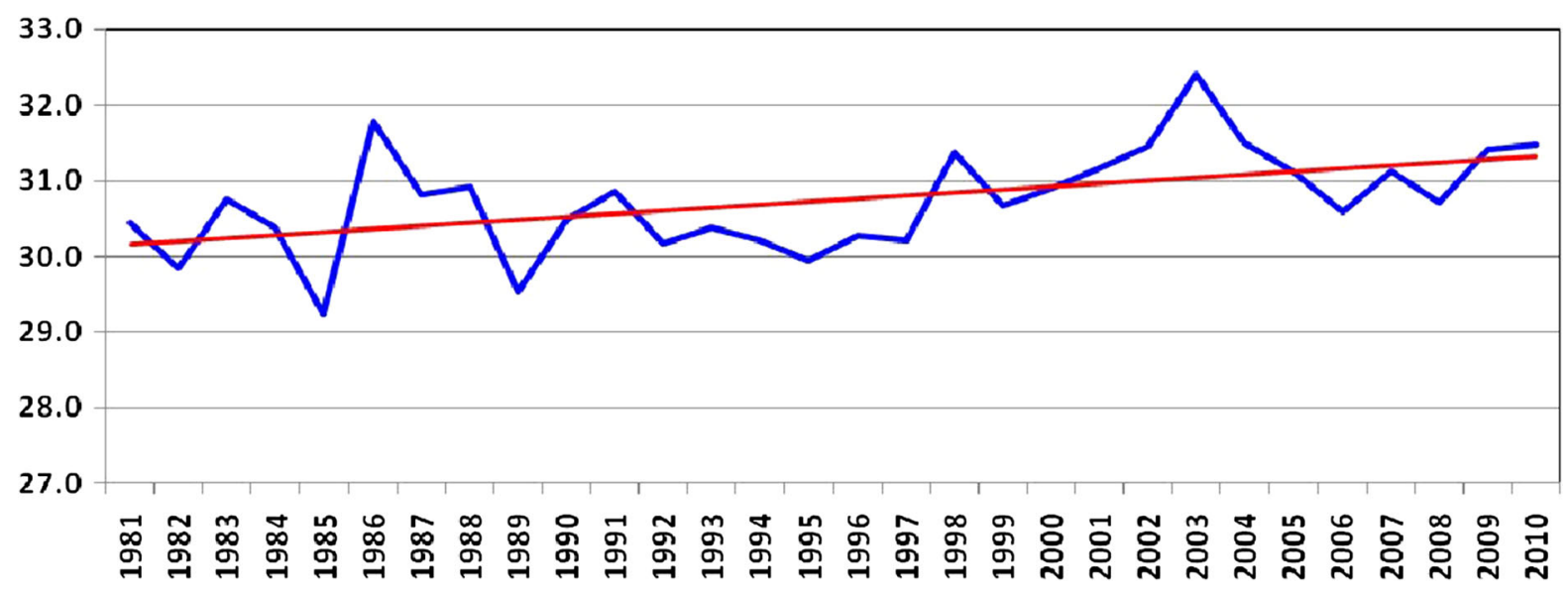

Fig. 3 Temperature trend for Kisarawe in centigrades (1981-2010)

Maglan 2015; Kashaigili et al. 2013a). Accordingly, encroaching the Pugu and Kazimzumbwi forest reserves for accessing ecosystem services as a coping strategy to climate change effects has been increasing at an alarming rate (Kashaigili et al. 2013a; Szreter and Woolcock 2004; Lupala and Maglan 2015; Lupala et al. 2014; Lazaro et al. 2013; Mngumi et al. 2014). The increasing forest encroachment in turn leads to decreasing forest cover and diminishing of ecosystem services with counterproductive effect to climate change adaptation and mitigation efforts (Kashaigili et al. 2013a; Lupala and Maglan 2015; Lupala et al. 2014).

The above findings shows how livelihoods of the Pugu and Kazimzumbwi forest reserves adjacent communities are intricately linked to the adjacent ecosystem services. This is substantiated by the fact that decreasing crop yields owing to climate change has led to the increasing extraction of adjacent ecosystem services as a survival strategy. Studies Lupala and Maglan (2015), Mngumi et al. (2014), Kashaigili et al. (2013b), indicate high dependence on ecosystem services for survival. These results resemble with findings by Roy et al. (2017). This is suggesting extractive dependency between communities adjacent to the Pugu and Kazimzumbwi forest reserves to its neighbouring ecosystem services. However, as theorized by Ernstson (2008) i.e. urban systems dependence on tangible (extractive) ecosystem services should be relatively weak compared to rural systems. To the contrary urban socioecological systems ought to potray non-extractive dependence i.e. more dependence on cultural ecosystem services (MEA 2005b; Ernstson 2008). It is thus surprising for the peri-urban i.e. Pugu and Kazimzumbwi forest reserves-socio-ecological system to potray high extractive dependence and yet it has heterogenous income earning alternatives (Table 2). This is further suggesting robust ecosystem services (both extractive and non-extractive)-based socioecological system resilience building options.

Social-cultural capacities versus climate change resilience building

This section presents some socio-cultural capacities of the Pugu and and Kazimzumbwi socio-ecological system and discusses their implicature on building resilience to climate change effects.

The respondents age distribution in the study area as shown in Fig. 1 corresponds to the national age structure composition, whereby youths from age 18-35 constitute $41 \%$, working population 36-60 constitute $44 \%$ and the elderly constitute $15 \%$. Notwithstanding that these readings (Fig. 4) excludes children, they portray a mixture of different age cohorts within the peri-urban settlements. The elderly cohort is relatively high compared to the national age 
Table 2 Respondent's occupation in the study area Source: Field work (October 2017-March 2018)

Fig. 4 Respondent's age. Source: Field work (October 2017-March 2018)

\begin{tabular}{llllr}
\hline Employment type & \multicolumn{2}{l}{ Study hamlet } & N $=147$ \\
\cline { 2 - 5 } & $\mathrm{n}=50$ & $\mathrm{n}=48$ & $\mathrm{n}=49$ & Total \% \\
& Nzasa $(\%)$ & Pugu-Kibaoni $(\%)$ & Kisarawe (\%) & \\
\hline Farming & 13 & 3 & 12 & 29 \\
Cattle keeping & 3 & 2 & 2 & 7 \\
Poultry husbandry & 3 & 4 & 5 & 12 \\
Casual labour & 3 & 3 & 9 & 16 \\
Public employee & 0 & 0 & 5 & 5 \\
Vegetable gardening & 4 & 2 & 5 & 11 \\
Tree nursery gardening & 1 & 0 & 1 & 2 \\
Brick making & 1 & 4 & 0 & 5 \\
Matching guys & 2 & 8 & 2 & 13 \\
Logging & 1 & 1 & 3 & 5 \\
Bee keeping & 1 & 1 & 6 & 10 \\
Charcoal making and selling & 1 & 2 & 6 & \\
\hline
\end{tabular}

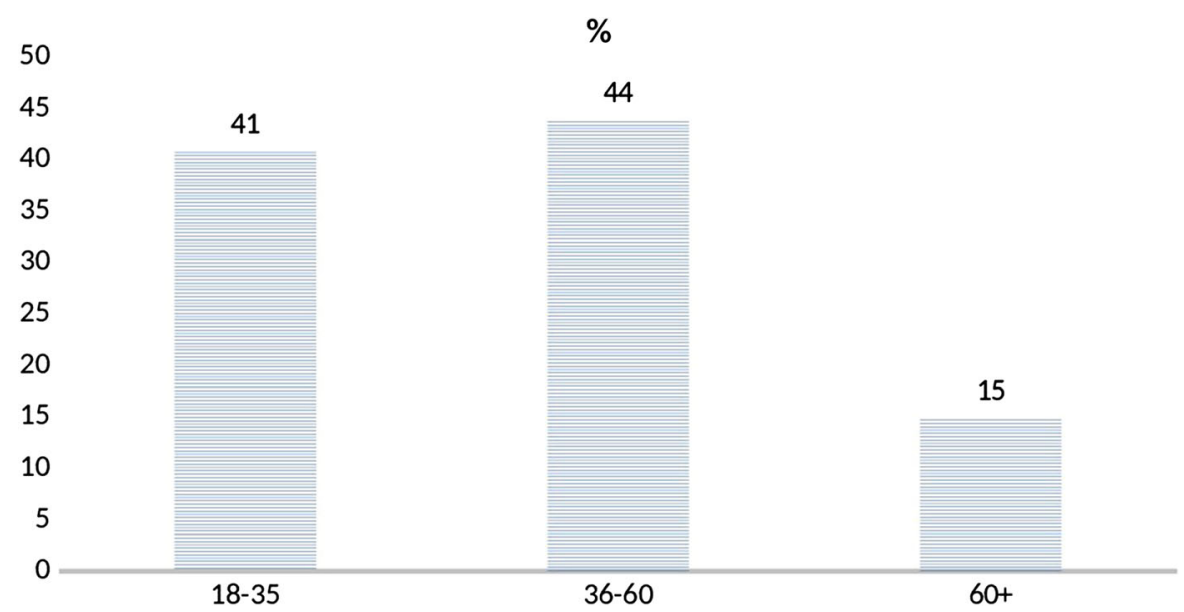

structure suggestively because the children cohort is not included. In resilience discourse having a mixture of different age cohorts in a socio-ecological system is positively regarded as it provide avenue for cross-age mentoring (Benard 1997). The elderly cohort for instance is traditionally believed to carry socioecological system memory and this is particularly imperative in the face of stress or environmental change (Barthel 2008). Therefore the socio-ecological memory through the elderly cohort can easily be transferred to the younger generation especially in different approaches by which the previous generations used to address similar stress to environmental change using traditional knowledges. In the study area faced by climate change stress, the elderly cohort will provide useful traditional knowledge on how to cope with climate change effects using locally available resources including ecosystem services. Other age cohort for instance the youths ought to cooperate with the elderly by imposing more uptodate modalities of combating climate change effects in liaison with other actors for building socio-ecological system resilience without creating counterproductive effects. 
Level of education being one of the cultural capital which tells to some extent the level of employability and flexibility and partly resilience was assessed at Pugu and Kazimzumbwi socio-ecological system as in Table 1.

Field work (October 2017-March 2018) A majority (59\%) of the community representatives in the three study hamlets (Nzasa, Pugu-kajungeni and Kisarawe) are having primary education (standard 1-7) Table 1. The second rank in education among community representatives was those who had got no formal education at all (21\%), followed by those who received secondary education (14\%) and the least proportion of community representatives was the proportion of those who were previlaged to acquire up to certificate training and above $(6 \%)$. The findings on education level (Table 1) in the study hamlets corresponds with previous studies at the same periurban forest reserves (Lazaro et al. 2013; Himada 2011). The findings on the level of education generally shows a positive indicator that majority of community representative (79\%) are having basic literacy knowledge of at least knowing how to read and write. On the other hand these findings suggests lack of flexibility of community members in seeking alternative or better

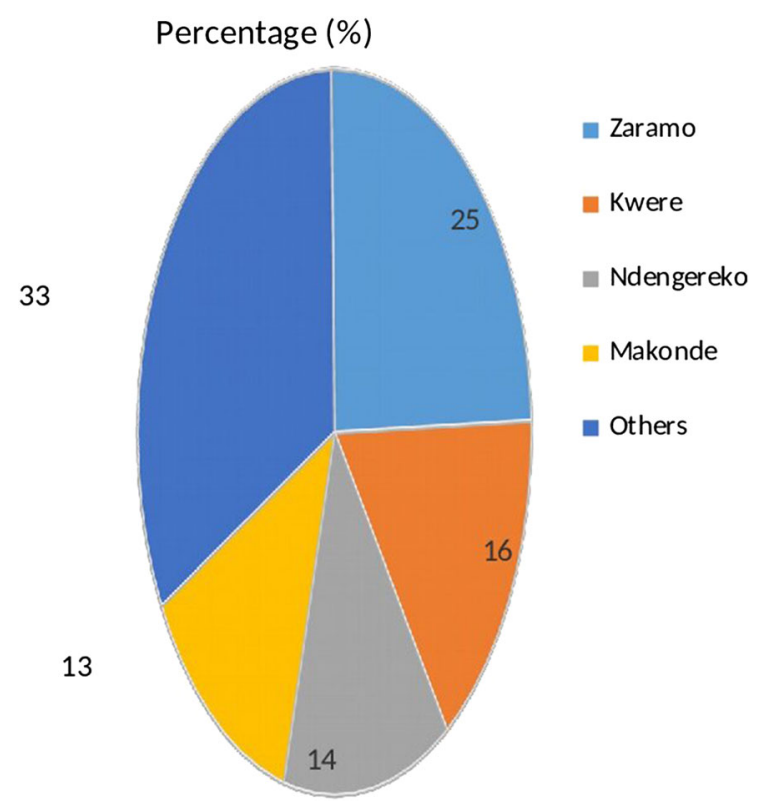

Fig. 5 Ethnic composition in the study area. Source: Field work (October 2017-March 2018) paying employment since majority have attained up to primary education. The level of education of community representatives further suggests considerable dependence on peri-urban ecosystem services due to weak employment flexibility. However, in resilience building perspective these scores on level of education at Pugu and Kazimzumbwi socio-ecological system are showing a positive community adaptive capacity as majority of community representatives having cognitive knowledge which can enable them to process information, perceive and interpret and thereby make higher quality decision towards addressing climate change effects.

Ethnic orientation one of the resilience related cultural adaptive capacity was explored. The findings are as shown in Fig. 5.

The findings reveal a hybrid ethnic composition in the peri-urban settlements of Dar es Salaam. The major ethnic group in the study area is Zaramo (25\%), followed by Kwere (16\%), Ndengereko (13\%) and Makonde (13\%). Other ethnic groups includes Matumbi, Chagga, Haya, Pare, Nyakyusa, Pogoro, Kurya, Sukuma, Hehe, Jita, Nyiramba, Masai, Makua and Nyamwezi who in total constitute $33 \%$ of community representatives. Other ethnic groups are not native in the area but rather migrated to the area mostly from up country (Bara) for diverse reasons. The ethnic hybridity in the Pugu and Kazimzumbwi socio-ecological system often taken for granted is an asset in resilience building perspective. In resilience thinking ethnic hybridity is often described as ethnic diversity and is believed to be one of the socioecological system 'adaptive capacities' in building resilience to shocks and stresses such as climate change as it is the case in the study area. The confluence of different ethnic groups in a given socioecological system is an asset in building resilience in that community by pulling together diverse coping strategies to climate change as there are community members with varied experiences on how to address such changes from different stand points.

Since occupation extent is theorized as one factor telling on the community dependence on ecosystem services, it was assessed in the peri-urban settlements of Dar es Salaam as shown in Table 2. 
Table 2 shows the distribution of employment across the three study hamlets within the Pugu and Kazimzumbwi socio-ecological system. A general picture of occupation and/employment in the study area shows a great diversity of income generating activities upon which individuals earn their living. Proportionally leaving aside scores across settlements farming is leading (29\%), followed by; casual labour $(16 \%)$, matching guys (13\%), poultry husbandry (12\%), vegetable gardening (11\%), charcoal making and selling (10\%), bee keeping (8\%), cattle keeping (7\%), logging (5\%), brick making (5\%) and public employee $(5 \%)$. These findings on employment are contrary to general employment statistics in Tanzania which indicates that majority about $70 \%$ of Tanzanians and particularly in rural areas are employed in agricultural activities. On the other hand these findings tally with studies done in the peri-urban areas of Dar es Salaam, showing that less than $50 \%$ of community representatives are relying on non agricultural related employment (Mngumi et al. 2014). In resilience discourse, the presence of multiple sources of income earning activities in a socio-ecological system is regarded as a positive adaptive capacity. This characteristic is one of the community (socio-ecological system) adaptive capacity providing conducive working ground for agents to act upon in building socioecological system resilience against climate change effects.

However, despite the occupation heterogeneity observed at the Pugu and Kazimzumbwi socioecological system (Table 2), the article further presents extractive dependency on ecosystem services leading to their decline and thereby causing maladaptation to climate change effects.

The findings in this section on cultural adaptive capacities at Pugu and Kazimzumbwi socio-ecological system has shown that the system has rich cultural diversity i.age, ethnicity, education and occupation which are promising in building resilience to climate change effects. This reasoning concurs with arguments by Sabatier (1992), that cultural diversity promotes the ability to build and increase the adaptive capacity for learning and adaptation to environmental change. This is suggesting that the Pugu and Kazimzumbwi socio-ecological system has positive cultural adaptive capacities imperative for building resilience for climate change effects but lies unexploited.
Ecosystem services and economic diversification opportunities

Economic diversity is one of the primary socioecological system adaptive capacity necessary for building resilience. This is imperative in areas where stress affects livelihood systems. As previously highlighted, one of the immediate effects of climate change at Pugu and Kazimzumbwi socio-ecological system is declining crop production and thereby diminishing livelihood options. Further, it was underscored that one of the consequence of declining livelihood options was increased forest encroachment and declining forest ecosystem services as a result. This study explored environmental friendly ecosystem baseddiverse economic options at the Pugu and Kazimzumbwi socio-ecological system forming part of its adaptive capacities in building resilience to climate change effects. Viable ecosystem-based (provisioning and cultural ecosystem services) climate friendly economic options at Pugu and Kazimzumbwi forest reserves-socio-ecological system includes bee keeping industry, art and craft tourism and nature tourism.

\section{Bee keeping industry}

Bee keeping is one of the inherent ecosystem based climate friendly livelihood options with potential for building community resilience against climate change effects at the Pugu and Kazimzumbwi socio-ecological system. In a focus group discussion held at Kisarawe, bee keeping was underscored as being among the viable livelihood options with threefold effects. One focus group participant at Kisarawe narrated

Bee keeping is helping us to earn a living as crop production is no longer reliable due to unpredictability of rainfall pattern. Through bee keeping we can be able to supplement our income and hence be able to sustain our daily needs. Another advantage of bee keeping at our forest is that it act as a "forest gurd" i.e. when bee hives are installed along the border or forest buffer zone due to fear of being stung by bees people who have no bee keeping equipment and training can not get closer to the forest and hence discouraging encroaching forest reserve to access ecosystem services. 
Thirdly, bee keeping by discouraging forest encroachment is indirectly contributing to climate change mitigation efforts through increased forest cover. Despite bee keeping industry being with ample potential for enhancing resilience to climate change effects at the peri-urban forests of Pugu and Kazimzumbwi there are challenges for realization of its full potential. One key informant at Kisarawe said

Its true that bee keeping is beneficial as it enables us to increase our income but we are operating at very small scale which does not earn us sufficient income. The problem is we dont have enough initial capital to install large number of bee hives. We thank God that GREEN VOICES NGO (Image $1^{1}$ ) gave us training on how to install bee hives and how to take care of bee hives and they further gave us six bee hives with bee keeping equipments for starting the project of bee keeping but because of having no capital the number of bee hives is still the same'.

Lack of capital for scaling up bee keeping also featured at the discussion with bee keeping officer at (KDC). The officer said

Bee keeping at Pugu and Kazimzumbwi socioecological system not only provide potential for enhancing local community resilience to climate change by widening community livelihood options but also offers opportunity for large scale bee keeping investment. These peri-urban forests offers large scale bee keeping potential

\footnotetext{
${ }^{1}$ One key informant at Kisarawe towards attending her bee hives at the Pugu and Kazimzumbwi Socio-ecological system (provisioning ecosystem services). Photo: Lazaro Mngumi; March 2018.
}

with an added advantage of a nearby market for honey and other related products (Dar es Salaam City) and near oversee gate way at Julius Nyerere International Airport and the Dar es Salaam harbour both within $30 \mathrm{~km}$ from the Pugu and Kazimzumbwi forest reserves. This is imperative especially in this fifth government regime in Tanzania which put emphasis on industrial development. The only challenge is capital for initial investment.

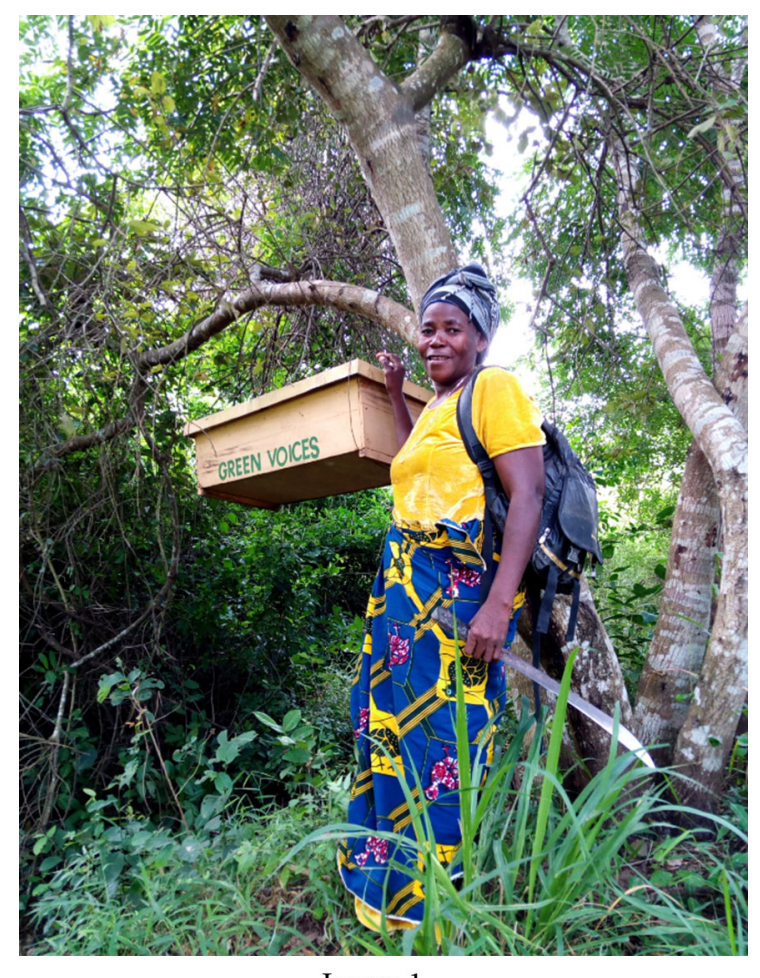

Image 1

As portrayed in Table 2 bee keeping is carried out by the small proportion of community representatives only $8 \%$. Since bee keeping provides livelihood options dissimilar to the main income earning activity (Biggs et al. 2015) (farming-Table 2), which is adversely affected by climate change it offers viable response diversity to climate change effects and hence needs to be promoted and upscaled at the Pugu and Kazimzumbwi-socio-ecological system so as to build community resilience to climate change effects. The argument of usefulness of bee keeping in enhancing resilience building are in line with findings by Tompkins et al. (2013). This would not only widen 
survival options during climate change stress but also improve forest conservation and mitigate climate change and thus bringing win-win-win outcome.

\section{Tourism industry}

Tourism is one of the viable economic activity identified at the Pugu and Kazimzumbwi socioecological system providing response diversity to climate change effects. Three major categories of ecosystem-based form of tourism were identified i.e. cultural tourism (food tourism, arts and crafts tourism) and nature tourism.

Under cultural tourism two major types were underscored during field study i.e. food tourism Image 2 and arts and crafts Image 3. Ecosystem services at Pugu and Kazimzumbwi forest reserves socio-ecological system offers diverse response livelihood options through cultural tourism. The fact that tourism was not mentioned as one of economic activities at Pugu and Kazimzumbwi forest reservessocio-ecological system (Table 2) shows how it is not well developed and only few people are involved in the community. It was also noted at an interview at Pugu-Kibaoni that those who engage themselves in supporting tourism by serving as tour guides are lowly paid to the extent that they can not support themselves through entirely depending on tourism. Another key informant at Kisarawe was of the same opinion as below

We receive little amount of money about 5000 Tsh (equivalent to 2 USD-authors own interpretation) to accompany tourists to visit tourist attraction sites for a day. This amount we receive is not enough to cater for ones daily needs so one has to be involved in other activities to be able to survive. Here at Kisarawe tourism industry is not as developed as in northern regions (Arusha, Kilimanjaro, Manyara and Tanga) where tour guides are well paid. The number of tourists coming to visit various attraction in our sites is very few making the work of guiding tourists not very much reliable.

District tourism officer at KDC echoed key informant discussion on underdevelopment of tourism industry in the District. The officer highlighted the vast potential on tourism industry that lie undeveloped which could widen livelihood options to communities, improve income poverty and build resilience to climate change. The district tourism officer further noted that his office has established some measures to to be implemented so as to boost up tourism industry at Pugu and Kazimzumbwi forest reserves socio-ecological system.

Tourism industry at Pugu and Kazimzumbwi forest reserves-socio-ecological system not only provide response diversity to climate change effects but it is itself diverse in nature as it can be done in diverse ways i.e. arts and crafts tourism (Image $3^{2}$ ), food tourism (Image $2^{3}$ ), nature tourism (Image $4^{4}$ ) and (Image $5^{5}$ ). Presence of diverse forms of tourism potential at the Pugu and Kazimzumbwi socioecological system stands to be the justification that tourism is one of its inherent yet latent adaptive capacities for building resilience to climate change effects that lies largely unexploited.

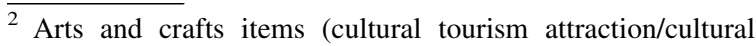
ecosystem services) at the Pugu and Kazimzumbwi socioecological system. Photo: Lazaro Eliyah Mngumi, February 2018.

3 Tourists being served local traditional food (food tourism/cultural ecosystem services) at the Pugu and Kazimzumbwi socioecological system. Photo: Lazaro Eliyah Mngumi, February 2018.

${ }^{4}$ Tourist sitting platform at Pugu forest reserve (cultural ecosystem services) at the Pugu and Kazimzumbwi socioecological system. Photo: Lazaro Eliyah Mngumi, February 2018.

5 Wild mammals cave at Pugu forest reserve (cultural tourism/cultural ecosystem services) at the Pugu and Kazimzumbwi socio-ecological system.Photo: Lazaro Eliyah Mngumi, February 2018.
} 

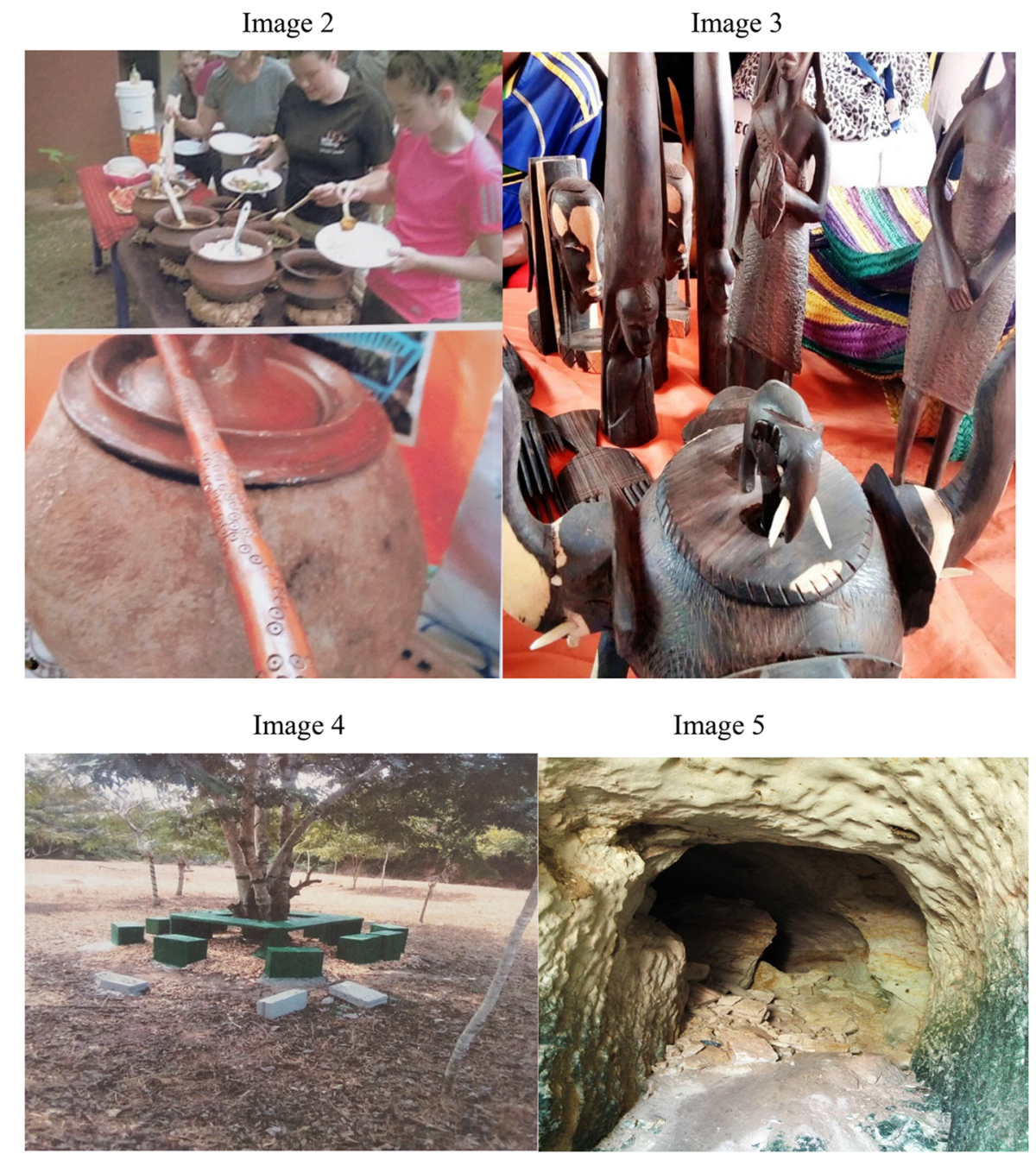

\section{Conclusion}

This article underscores two primary conclusions. Firstly, peri-urban socio-ecological system in developing cities like Dar es Salaam exhibit strong extractive dependency on ecosystem services. This type of people-ecosystem services relationship, despite straying from theoretical conceptions of strong nonextractive dependency in peri-urban setting i.e. strong dependency on cultural ecosystem services instead, it poses unique challenge on efforts geared to address climate change effects in these areas as it has been the case in the Pugu and Kazimzumbwi socio-ecological system. Climate change at the Pugu and Kazimzumbwi socio-ecological system affects livelihood systems and hence increases dependency on ecosystem services even further. As dependency on ecosystem services increases as one of the autonomous adaptation strategies it in turn leads to diminishing of peri-urban ecosystem services and maladaptation to climate change effects. This in turn suggests robust ecosystem services based resilience building to climate change effects which will benefit both climate change adaptation and ecosystem services restoration.

Secondly, the peri-urban areas of Pugu and Kazimzumbwi socio-ecological system has an imperative set of adaptive capacities i.e. both cultural and ecosystem based necessary for building resilience to climate change effects. However, despite presence of diverse socio-ecological adaptive capacities little if any has been done in deploying them in building resilience to climate change effects. This is why I 
describe these adaptive capacities as 'latent' adaptive capacities as they require to be activated by human agency and thereby bring about the desired effect in building resilience to climate change effects at the Pugu and Kazimzumbwi socio-ecological system. This further suggests exploration of the nature and the role of agency in building resilience to climate change effects at the Pugu and Kazimzumbwi socioecological system.

In light of this article, it is suggested therefore that peri-urban areas and their associated ecosystems and so ecosystem services need to be given due attention in relevant policy platforms. This will enable transforming their inherent latent adaptive capacities into a climate change resilient peri-urban socio-ecological system. Furthermore, the consideration of peri-urban areas into policy discourses will yield into enormous benefits to the increasing urban planning challenges.

Acknowledgements Open access funding provided by Swedish University of Agricultural Sciences. This article was written as part of the urban governance and municipal services project under the partnership between the Institute of Human Settlements Studies (IHSS) of Ardhi University Tanzania and the Faculty of Natural Resources and Agricultural Sciences of Swedish University of Agricultural Sciences (SLU) in Sweden. I thank a team of my supervisors, Antoienette Warnbard, Makarius Victor Mdemu and Zeinab Eildeen for their comments, suggestions and support at the time I was developing concepts for my project and writing of this article. Lastly but not the least I give my sincere thanks to my fellow PhD candidates; Happiness Mlula, Edson Sanga, Said Nuhu and Maglan Seng'enoi who shared their critical insights in shaping this piece of work.

\section{Compliance with ethical standards}

Conflict of interest I Lazaro Eliyah Mngumi hereby state that there is no any form of competing interest in the whole research undertaking which led to the writing of this article.

Treatment of human subjects in the research process statement I Lazaro Eliyah Mngumi hereby state that there is no any form of experiment done involving human/animal in this research. I hereby state that all methods as described in the methods section were carried out in accordance with relevant guidelines and regulations

Informed consent Lastly I hereby confirm that 'informed consent' was obtained from all subjects/human who participated as respondents and they were all above 18 years and that any form of picture or image presented was done by seeking prior permission from the respective person. Additionally, the approval for research to be conducted using the methods was provided by the relevant authorities as separately attached.
Open Access This article is distributed under the terms of the Creative Commons Attribution 4.0 International License (http:// creativecommons.org/licenses/by/4.0/), which permits unrestricted use, distribution, and reproduction in any medium, provided you give appropriate credit to the original author(s) and the source, provide a link to the Creative Commons license, and indicate if changes were made.

\section{References}

Adger, W. N. (2000). Social and ecological resilience: Are they related? Progress in Human Geography, 24(3), 347-364.

Almedom, A. M. (2004). Factors that mitigate war-induced anxiety and mental distress. Journal of Biosocial Science, 36(4) ,445-461.

Barthel, S. (2008). Recalling urban nature: Linking city people to ecosystem services. Frescati: Systemekologiska institutionen.

Benard, B. (1997). Turning it around for all youth: From risk to resilience. ERIC/CUE Digest, Number 126.

Berkes, F. (2007). Understanding uncertainty and reducing vulnerability: Lessons from resilience thinking. Natural Hazards, 41(2), 283-295.

Berkes, F., Folke, C., \& Colding, J. (2000). Linking social and ecological systems: Management practices and social mechanisms for building resilience. Cambridge: Cambridge University Press.

Berkes, F., \& Ross, H. (2013). Community resilience: Toward an integrated approach. Society and Natural Resources, 26(1), 5-20.

Biggs, R., Schlüter, M., \& Schoon, M. (2015). Applying resilience thinking: Seven principles for building resilience in social-ecological systems. Cambridge: Cambridge University Press.

Birkmann, J., Garschagen, M., Kraas, F., \& Quang, N. (2010). Adaptive urban governance: New challenges for the second generation of urban adaptation strategies to climate change. Sustainability Science, 5(2), 185-206.

Burgess, N. D. (2000). Global importance and patterns in the distribution of coastal forest species. Kenya: Coastal Forests of East Africa.

Burgess, N., \& Dickinson, A. (1993). Coastal Forest Research Programme, Site Description and Evaluation: Kazimzumbwi Forest, Kisarawe District, Tanzania: The Society for Environmental Exploration and University of Dar es Salaam. London: Thames House.

Clarke, G. \& Dickinson, A. (1995). Status reports for 11 coastal forests in coast region, Tanzania Frontier-Tanzania Technical Report No. 17. 17. The Society for.

Ernstson, H. (2008). In Rhizomia: Actors, networks and resilience in urban landscapes. Systemekologiska institutionen.

Folke, C. (2006). Resilience: The emergence of a perspective for social-ecological systems analyses. Global Environmental Change, 16(3), 253-267.

Folke, C., Colding, J., \& Berkes, F. (2003). Synthesis: Building resilience and adaptive capacity in social-ecological systems. Navigating Social-Ecological Systems: Building Resilience for complexity and Change, 9(1), 352-387. 
Freudenburg, W. R., \& Gramling, R. (1994). Natural resources and rural poverty: A closer look. Society and Natural Resources, 7(1), 5-22.

Goldstein, B. E. (2008). Skunkworks in the embers of the Cedar Fire: Enhancing resilience in the aftermath of disaster. Human Ecology, 36(1), 15-28.

Gooch, M., Rigano, D., Butler, J., \& Cullen, L. (2010). Developing and refining indicators of community-scale resilience to changing water quality. Cairns: Marine and Tropical Sciences Research Facility (MTSRF).

Gunderson, L. H. (1997). Resilience in ecosystems, institutions, and societies.

Gunderson, L. H. \& Holling, C. S. (1995). Barriers and bridges to the renewal of ecosystems and institutions. The Columbia University Press, 593 p.

Hegney, D., Ross, H., Baker, P., Rogers-Clark, C., King, C., Buikstra, E., et al. (2008). Identification of personal and community resilience that enhance psychological wellness: A Stanthorpe study. Toowoomba, QLD: University of Southern Queensland.

HIMADA. (2011). A detailed study on Information and Knoeledge needs for the conservation of Pugu and Kazimzumbwi forest reserves. Tanzania: Dar es Salaam.

Humphrey, C. R., Berardi, G., Carroll, M. S., Fairfax, S., Fortmann, L., Geisler, C., et al. (1993). Theories in the study of natural resource-dependent communities and persistent rural poverty in the United States. Persistent Poverty in Rural America, 4, 136-172.

IPCC. (2007). Synthesis report. Cambridge: Cambridge University Press.

IPCC. (2014). Climate change 2014-Impacts, adaptation and vulnerability: Regional aspects. Cambridge: Cambridge University Press.

Kashaigili, J., Levira, P., Liwenga, E. \& Mdemu, M. (2013a). Analysis of climate variability, perceptions and coping strategies of Tanzanian coastal forest dependent communities.

Kashaigili, J. J., Mdemu, M. V., Nduganda, A. R. \& Mbilinyi, B. P. (2013b). Integrated assessment of forest cover change and above-ground carbon stock in Pugu and Kazimzubwi forest reserves, Tanzania. American Journal of Climate Change, 3, 212-222.

Kulig, J. C., Hegney, D., \& Edge, D. S. (2009). Community resiliency and rural nursing: Canadian and Australian perspectives. Rural nursing: concepts, theory and practice (3rd ed., pp. 385-400). New York: Springer.

Lamarque, P., Tappeiner, U., Turner, C., Steinbacher, M., Bardgett, R. D., Szukics, U., et al. (2011). Stakeholder perceptions of grassland ecosystem services in relation to knowledge on soil fertility and biodiversity. Regional Environmental Change, 11(4), 791-804.

Lazaro, M., Silas, S. R., \& Emma, L. (2013). Community perceptions and willingness to accept and execute REDD + initiative: The case of Pugu and Kazimzumbwi forest reserves, Tanzania. Cross-Cultural Communication, $9(3), 48-54$.

Lu, F. (2010). Patterns of indigenous resilience in the Amazon: A case study of Huaorani hunting in Ecuador. Journal of Ecological Anthropology, 14(1), 5-21.

Lupala, J. M. (2016). The effects of peri-urbanization on Pugu and Kazimzumbwi forest reserves, Dar es Salaam,
Tanzania. International Journal of Physical and Human Geography, 3(2), 49-92.

Lupala, J. \& Maglan, C. (2015). Climate change and its effects on livelihood strategies of peri-urban coastal communities in Tanzania. Pyrex Journal of geography and Regional Planning, 1(1), 1-10.

Lupala, J. M., Mdemu, M. V., \& Butungo, S. P. (2014). Effects of peri-urban land use changes on forest ecosystem services: The case of settlements surrounding Pugu and Kazimzumbwi Forest Reserves in Tanzania. Journal of Geography and Geology, 6(4), 231.

Maida, C. A. (2007). Sustainability and communities of place. New York: Berghahn Books.

MEA. (2005a). Ecosystem and human well-being: Biodiversity synthesis. Washington, DC: World Resources Institute.

MEA. (2005b). Ecosystems and human wellbeing: The assessment series (four volumes and summary). Washington: Island Press.

Mngumi, L., Shemdoe, R. \& Liwenga, E. (2014). Community dependence on forest resources and its bearing on REDD + initiative in Pugu and Kazimzumbwi forest reserves, Tanzania. African Resources Development Journal, 1-19.

Munang, R., Thiaw, I., Alverson, K., Mumba, M., Liu, J., \& Rivington, M. (2013). Climate change and Ecosystembased Adaptation: A new pragmatic approach to buffering climate change impacts. Current Opinion in Environmental Sustainability, 5(1), 67-71.

Munroe, R., Roe, D., Doswald, N., Spencer, T., Möller, I., Vira, B., et al. (2012). Review of the evidence base for ecosystem-based approaches for adaptation to climate change. Environmental Evidence, 1(1), 13.

Norgaard, R. B. (1994). Development betrayed. The end of progress and a coevolutionary revisioning of the future. London: Routledge.

Norris, F. H., Stevens, S. P., Pfefferbaum, B., Wyche, K. F., \& Pfefferbaum, R. L. (2008). Community resilience as a metaphor, theory, set of capacities, and strategy for disaster readiness. American Journal of Community Psychology, 41(1), 127-150.

Ricci, L. (2015). Reinterpreting sub-saharan cities through the concept of adaptive capacity: An analysis of autonomous adaptation in response to environmental changes in Periurban areas. Berlin: Springer.

Ross, H., Cuthill, M., Maclean, K., Jansen, D. \& Witt, B. (2010). Understanding, enhancing and managing for social resilience at the regional scale: Opportunities in North Queensland. Report to the Marine and Tropical Sciences Research Facility, Reef and Rainforest Research Centre Limited, $186 \mathrm{p}$.

Roy, M. K., Shemdoe, R., Hulme, D., Mwageni, N. \& Gough, A. (2017). Climate change and declining levels of green structures: Life in informal settlements of Dar es Salaam, Tanzania. Landscape and Urban Planning, 180, 282-293.

Sabatier, P. A. (1992). Governing the commons: The evolution of institutions for collective action. In O. Elinor (Ed.), American Political science review (Vol. 86, pp. 248-249). Cambridge: Cambridge University Press.

Salem, M. (2015). Peri-urban dynamics and land-use planning for the Greater Cairo Region in Egypt. Sustainable Development (2 Volume Set), 168, 1109. 
Secretariat, P.-A. S. (2017). Urban poverty and climate change in Dar es Salaam, Tanzania.

Szreter, S., \& Woolcock, M. (2004). Health by association? Social capital, social theory, and the political economy of public health. International Journal of Epidemiology, 33(4), 650-667.

TFCG. (2013). Two surveys of the plants, birds and forest condition of Pugu and Kazimzumbwi Forest Reserves in 2011 and 2012. In: 36, T. T. P. (ed.).

Tidball, K., \& Stedman, R. (2013). Positive dependency and virtuous cycles: From resource dependence to resilience in urban social-ecological systems. Ecological Economics, 86(1), 292-299.

Tompkins, E. L., Mensah, A., King, L., Long, T. K., Lawson, E. T., \& Hutton, C. W. (2013). An investigation of the evidence of benefits from climate compatible development. Working paper no. 124. Center for Climate Change Economics and Policy, University of Leeds.

Ullsten, O., Gustave speth, J., \& Chapin, F. S., III. (2004). Options for enhancing the resilience of northern countries to rapid social and environmental change: A message to policy makers. AMBIO: A Journal of the Human Environment, 33(6), 343.

Vignola, R., Locatelli, B., Martinez, C., \& Imbach, P. (2009). Ecosystem-based adaptation to climate change: What role for policy-makers, society and scientists? Mitigation and Adaptation Strategies for Global Change, 14(8), 691.

Wandl, A., \& Magoni, M. (2016). Sustainable planning of periurban areas: Introduction to the special issue. Planning Practice and Research, 32(1), 1-3.

Zimmerer, K. S. (1994). Human geography and the "new ecology": The prospect and promise of integration. Annals of the Association of American Geographers, 84(1), 108-125.

Publisher's Note Springer Nature remains neutral with regard to jurisdictional claims in published maps and institutional affiliations. 